\title{
Occurrences and frequency of fungi and detection of mycotoxins on poultry rations in Yemen
}

\author{
Hamid Moh Algabr ${ }^{1,3,5^{*}}$, Amin Alwaseai ${ }^{4}$, M. A. Alzumir ${ }^{1}$, A. A. Hassen ${ }^{1}$ and S. A. Taresh ${ }^{2}$
}

\begin{abstract}
Background: Fungi were grown elsewhere in the soil, water, and food, and fungi cause many of the problems during growth on food in stores. This study investigated the occurrence and frequency of fungi in four governorates in Yemen. Twenty-nine site samples of poultry rations were collected from four governorates in Yemen, in order to study the occurrence of fungi and production of mycotoxins.

Results: Fungi associated and isolated from poultry ration were identified as Aspergillus flavus, Aspergillus niger, Aspergillus candidus, Aspergillus carneus, Fusarium moniliforme, Penicillium chrysogenum, Penicillium spp., Mucor sp., and Rhizopus nigricans. Frequency from Sana'a companies showed that F. moniliforme was significantly dominant (38.82\%), followed by Aspergillus flavus (15.84\%) and Aspergillus candidus (16.44\%). While, from Taiz companies showed that Aspergillus flavus significantly was dominant (35.78\%), followed by Fusarium moniliforme (29.26\%). The results indicated that the samples collected from Taiz companies showed that high concentrations of aflatoxins ranged 26-45 ppb, than other samples which were collected from Sana'a while the fumonisins were 1-5.9 ppm. Moreover, lower concentrations of fumonisins were collected from Taiz companies $(0.65-0.93 \mathrm{ppm})$. Aflatoxins in samples collected from farmer's poultry in Taiz and Dhamar were $42.5 \mathrm{ppb}$. Also in samples from Sana'a and Ibb, the high concentration found is $39 \mathrm{ppb}$. The maximum significant mean of aflatoxins production was $25.2 \mathrm{ppb}$ at $25^{\circ} \mathrm{C}$. Aflatoxins production was decreased at lower or higher tested temperature $(3.6,9.93 \mathrm{ppb})$ at $15^{\circ} \mathrm{C}$ and $35^{\circ} \mathrm{C}$ respectively. Similarly, fumonisin produced at $25^{\circ} \mathrm{C}$ was $1.65 \mathrm{ppm}$, but decreased at lower or higher temperatures tested 1.3 and $0.54 \mathrm{ppm}$ at $\left(15^{\circ} \mathrm{C}\right.$ and $35^{\circ} \mathrm{C}$ respectively.

Conclusion: This study found that the poultry rations were highly contaminated by fungi. Moreover, some of the fresh samples contain high level of aflatoxins and fumonisin. On the other hand, this level may cause significant economic losses in the poultry industry in Yemen.
\end{abstract}

Keywords: Fungi, Poultry ration, Fusarium, Aspergillus, Aflatoxins, Fumonisin

\section{Introduction}

Many strains of fungi can grow in food stores and can cause many problems on food or in human and animal health. Some fungi, Aspergillus (A.), Penicillium (P.), and Fusarium ( $F$.), are isolated from the corn grains and sunflower seeds (Abdel-mallek et al. 1993; Nepote et al. 1997; Castella et al. 1999a). While Nijs and De-nijs (1997) found isolated Fusarium spp., and found in 83\%

\footnotetext{
* Correspondence: han-chin@hotmail.com

'Plant Protection, Agriculture College Sana'a University, Sana'a, Yemen

${ }^{3}$ Biology Department, Education College Albayda'a University, Albayda'a, Yemen

Full list of author information is available at the end of the article
}

of 69 cereal samples from batches intended for food or feed production and harvested in the Netherlands. Twelve secondary metabolites from Fusarium spp. are indicated. Also, Bottalico (1997) reported that several Fusarium species occurring on pre-harvest cereals in Europe cause widespread stalk and ear rot of maize and head blight of small cereals. Magnoli et al. (1999) and Park et al. (1999) found nine species of Fusarium, and the highest counts were for $(F$.) dlamini, Gibberella fujikuroi var. subglutinans, G. fujikuroi, and F. nygamai. Strains of G. fujikuroi, F. nygamai, and F. proliferatum. Orsi et al. (2000) analyzed the mycoflora in stored grain samples of maize and was the most prevalent species 
(59.2\%) of Fusarium. The mycotoxicological evaluation indicated contamination with fumonisin B1 and fumonisin B2. Dasilva et al. (2000) reported that the results show a predominance of the genera Phoma, Aspergillus, Fusarium, and Rhizopus. The species most frequently found were Aspergillus flavus and Fusarium moniliforme of the samples analyzed. Nepot et al. (1997) and Chau et al. (1997) analyzed maize samples collected and found that the high percentage of fungi were Aspergillus flavus and A. parasiticus. While Castella et al. (1999b) showed the species Aspergillus, penicillium, and Fusarium were the most frequent genera. The effect of temperature and moisture content on occurrence of fungi on grains was investigated by Desjardins et al. (2000) and Orsi et al. (2000), and showed that the Fusarium spp. have significant negative correlations with temperature and relative humidity of the air. The most important factors are grain moisture content, and the optimum temperature for $(A$.) flavus to grow is $80-90^{\circ} \mathrm{F}$.

Concomitant incidents of toxicities in geese and broiler chickens associated with ochratoxin-A contaminated corn [maize] at farms are reported. A feeding of a shipment of imported maize caused a severe reduction in growth and increased mortality in geese, and increased mortality in broilers (Nepote et al. 1997; Mde and De-Nijs, 1997; Bottalico, 1997; Chau et al. 1997; MEdi et al. 1997; Pascale et al. 1999). Mycotoxins are fungal metabolites that are toxic when consumed by animals, including human beings. Aflatoxins are powerful tasteless, odorless, and colorless mycotoxins, which are chemical metabolites produced by certain strains of Aspergillus fungi. Fumonisins, produced by Fusarium moniliforme [Gibberella fujikuroi] and F. proliferatum (Begum and Samajpati, 2000; Medina-Martinez and Martinez, 2000; Kpodo et al. 2000) of the currently identified fumonisins, B1, B2, and B3, are the most abundant in naturally contaminated foods and feeds, and fumonisin B1 (FB1) generally comprises $75 \%$ of the total content (Proctor et al. 1999; Abbas et al. 1999). Reports on suspected damage in poultry farms caused by contaminated poultry rations by mycotoxins have been frequently made by farmers in Sana'a District, and samples contaminated by mold were delivered at the Faculty of Agriculture Labs-Sana'a University. Aflatoxicosis is a poisoning that results from ingestion of aflatoxins in contaminated food or feed. Several studies have reported the negative effect of aflatoxins in birds including reduction in performance, pathologic alterations in important organs such as the liver and kidneys and also the interference in immune system of birds. Aflatoxicosis has the same toxic effects in poultry as it does in mammals. A dose of $0.25 \mathrm{ppm}$ of aflatoxins in turkey poults and ducklings impairs growth, and a dose of $1.5 \mathrm{ppm}$ in broilers and $4 \mathrm{ppm}$ in Japanese quail has a negative effect on growth. Aflatoxins are also cancer promoters and an immunosuppressant factor. Effects are possible on poultry and small swine at $20 \mathrm{ppb}$. The toxins may occur in storage under conditions favorable for the growth of the toxin-producing fungi; these fungi commonly attack grains and can grow at temperatures from slightly above freezing to about $86^{\circ} \mathrm{F}$. Toxins such as T-2 and HT-2 are produced over a temperature range of $46^{\circ} \mathrm{F}$ to $77^{\circ} \mathrm{F}$, with the maximum production at temperatures below $59^{\circ} \mathrm{F}$. Conditions that favor to aflatoxin are the invasion of corn by Aspergillus flavus in the field and drought stress or damage to the corn ear by ear worms or other insects, birds, hail, or early frost. High temperatures, high relative humidity around the kernels, and kernel moisture below 30\% (wet basis) are ideal conditions for fungal invasion of the kernel. The optimum temperature for aflatoxin production in storage is between $25{ }^{\circ} \mathrm{C}$ and $32{ }^{\circ} \mathrm{C}\left(77^{\circ} \mathrm{F}\right.$ and $\left.90{ }^{\circ} \mathrm{F}\right)$. The effect of moisture and temperature on mycotoxins secretion by fungi (Christensen, 1969) studied some strains Aspergillus flavus Aspergillus glaucus, A. candidus, and A. flavus-ory$z a e$, and penicillium to producing aflatoxins and found with moisture contents of 17 to $20 \%$ and at $12^{\circ} \mathrm{C}$ and $27{ }^{\circ} \mathrm{C}$ for various lengths of time. In most of the tested, A. glaucus and $A$. candidus predominated. In some samples, A. flavus and penicillium increased very little if at all, even though the moisture content and temperature were favorable to them, whereas in other samples stored under similar condition, one or the other of these predominated. Tsai and Yu (1999) also investigated the Aspergillus parasiticus and found that aflatoxin was also both produced sooner and degraded more rapidly at aw $=0.98$. After moisturization and incubation of these commercial samples at $28{ }^{\circ} \mathrm{C}$ for 29 days, the incident rates of aflatoxigenic molds increased to $65 \%$ and $52 \%$ by plate count and ELISA, respectively. While Ryu and Bullerman (1999) studied the effects of temperatures cycling between $5{ }^{\circ} \mathrm{C}$ and $20{ }^{\circ} \mathrm{C}, 10{ }^{\circ} \mathrm{C}$ and $25{ }^{\circ} \mathrm{C}$, and $15{ }^{\circ} \mathrm{C}$ and $30^{\circ} \mathrm{C}$ on the production of fumonisin B1 (FB1) and ergosterol by Fusarium moniliforme and Fusarium proliferatum on rice. Also Orsi et al. (2000) reported that Fusarium spp. showed significant negative correlations with mean temperature and relative humidity of the air. Many of the problems appeared in poultry farmers and caused different diseases in poultry as well as death in the poultry in big numbers or showed dwarfed chicken in the market. So this study investigated this problem which caused the big losses in the economy. Hence, this study is the first study that aims to investigate the contamination of poultry rations (ground maize) by fungi and mycotoxins in four governorates (Sana'a, Dhamar, Ibb, and Taiz) of Yemen and under different environmental conditions at stores of poultry rations supply companies and at farmer's poultry farms. Methods of detecting mycotoxins in general are enzyme-linked immuno-sorbent assay (ELISA). The later method only is 
available and therefore is used. Recommendations on minimizing mycotoxins are to be suggested.

\section{Materials and methods Location and collection samples}

Twenty-nine site samples of poultry rations were collected from four Yemeni Governorates, namely, Sana'a, Taiz, Ibb, and Dhamar. Samples were randomly taken from different stores of companies which imported poultry rations and from small farmer's poultry farms. $1 \mathrm{~kg}$ ration for each sample was collected and transferred into plastic sealed bags and was taken for further analysis at the Plant Pathology Laboratory of the Faculty of Agriculture, Sana'a University.

\section{Isolation of fungi}

Poultry rations-associated fungi were isolated according to the method described by Reinaldo et al. (2000) Stock solution containing $10 \mathrm{~g}$ of each poultry ration sample was added into $90 \mathrm{ml}$ sterilized distilled water to obtain a 10-1 stock dilution and shaken manually, from which 10-fold serial dilutions up to 10-4 were made using the same diluents $1 \mathrm{ml}$ volumes of each dilution were added and spread onto Petri dishes containing 10-15 ml Czapek's medium (sodium nitrite $2 \mathrm{~g}$, potassium chloride $0.5 \mathrm{~g}$, magnesium sulfate $0.5 \mathrm{~g}$, sucrose $30 \mathrm{~g}$, dipotassium phosphate $1 \mathrm{~g}$, ferrous sulfate $0.1 \mathrm{~g}$ dissolved in $1000 \mathrm{ml}$ distilled water). Each treatment was replicated three times. Plates were then incubated at $25{ }^{\circ} \mathrm{C}$ for 7 days and examined daily for colonies frequency of prevailing fungi.

\section{Identification of fungi}

Each colony initiated from single isolated spore was transferred into slant of Czapek's medium for identification and further investigation. The isolated fungi were identified up to the species level according to Alexopoulos and Mims (1979), Pitt (1979), AUMC (2001), and Pitt and Hocking (2013). Pure cultures grown onto Czapek slants were kept at low temperature $\left(5^{\circ} \mathrm{C}\right)$ to further study fungi such as Fusarium moniliforme and Aspergillus flavus.

\section{Occurrence and frequency of fungi}

Contamination or fungal occurrence frequency was recorded for each sample. Fungal occurrence frequency was recorded as colony count number for each dilution and determined as percentage of each fungus frequency occurrence for each sample. Data were analyzed using SAS (statistical analysis system) software program for all designs included in the experiments.

\section{Determination of moisture}

The moisture content (M.C.) of ration samples was determined according to the method described by Melcion et al. (1997) as follows: $10 \mathrm{~g}$ of ration samples was accurately weighted and dried in the oven at $130{ }^{\circ} \mathrm{C}$ for $4 \mathrm{~h}$, then reweighed.

Moisture content percentage of the ration was calculated on a dry weight basis as follows:

Moisture content $\%=\frac{A-B}{A} X 100$

Where

$A=$ the weight of the sample before drying.

$B=$ the weight of the sample after drying.

\section{Chemicals and equipment}

Elisa Kits and standard of aflatoxins and fumonisin were purchased from (R-Biopharm Company, Germany). Aspergillus flavus and Fusarium moniliforme were isolated from maize and identified in Plant Pathology Laboratory, Agriculture College, Sana'a. Methanol, filter paper Whatman 1 , and micropipettes were purchased from, without border company, Sana'a, Yemen.

\section{Determination of aflatoxins and fumonisins in poultry ration samples collected from four governorates Preparation of samples}

Collected samples were stored in a cool place, protected from light. Each representative sample (according to accepted sampling techniques) was ground and thoroughly mixed prior to proceeding with the extraction procedure. Extraction was done as follows:

- Weigh of $10 \mathrm{~g}$ of ground sample added into a suitable container containing $50 \mathrm{ml}$ of $70 \%$ methanol.

- Samples were shaken vigorously for 3 min.

- Extract was filtered through Whatman No. 1 filter.

- Filtrate of $1 \mathrm{ml}$ was diluted to in $1 \mathrm{ml}$ distilled water.

- $50 \mu \mathrm{l}$ of the diluted filtrate was used per well in the test.

\section{Test procedure}

Elisa technique was used for determination of the level of mycotoxins using R-Biopharm, Germany kits (RIDASCREEN FAST) at the Labs of Yemen Standardization Metrology and Quality Control Organization as follows:

- A sufficient number of wells were inserted into the micro-well holder for all standards and samples to be run. Standards and sample positions were recorded.

- $50 \mu \mathrm{l}$ of each standard or prepared sample were pipetted into separate wells and a new pipette tip was used for each standard or sample.

- $50 \mu \mathrm{l}$ of enzyme conjugate was added to the bottom of each well. 
- $50 \mu \mathrm{l}$ of anti-aflatoxin antibody solution was added to each well. The plate was gently mixed by rocking manually and incubated for $5 \mathrm{~min}( \pm 0.5)$ at room temperature $\left(20-25^{\circ} \mathrm{C} / 68-77^{\circ} \mathrm{F}\right)$.

- The liquid was dumped out of the wells into a sink. The micro-well holder was taped upside down onto a clean filter towel (three times in a row) to remove all remaining liquid from the wells. Using a wash bottle or multi-channel pipette, the wells were filled $(250 \mu \mathrm{l}$ per well) with distilled water or washing buffer.

- The wells were discharged again, and all remaining liquid was removed. The washing step was repeated two more times.

- Tow drops (alternatively $100 \mu \mathrm{l}$ ) of substrate/ chromogen were added to each well, were mixed gently by rocking the plate manually, and were incubated for $5 \mathrm{~min}( \pm 0.5)$ at room temperature $\left(20-25^{\circ} \mathrm{C} / 68-77^{\circ} \mathrm{F}\right)$ in the dark.

- Tow drops (alternatively $100 \mu \mathrm{l}$ ) of stop solution added to each well and mixed gently by rocking the plate manually, and the absorbance at $450 \mathrm{~nm}$ was measured by ELISA reader against an air blank within 10 min and compared with the FAO standard.

\section{Effect of temperature on aflatoxin and fumonisin production in poultry ration samples}

Each isolate of Aspergillus flavus and Fusarium moniliforme was grown on natural substrate, $100 \mathrm{~g}$ of poultry ration, in $250 \mathrm{ml}$ Erlenmeyer flasks. This substrate was prepared by autoclaving at $121{ }^{\circ} \mathrm{C}$ for 30 min with $35 \mathrm{ml}$ of distilled water. After cooling, poultry rations were inoculated with an aqueous conidial suspension $(1 \mathrm{ml})$ of (106) spores obtained from Czapek's medium agar (CMA) cultures. Three flasks of every isolate were inoculated and incubated in darkness at 15,25 , and $35{ }^{\circ} \mathrm{C}$ for 28 days. To avoid clump formation, the flasks were hand-shaken during the first days of incubation.

After the incubation period, these cultures were dried at $60{ }^{\circ} \mathrm{C}$ for $48 \mathrm{~h}$, finely ground with a warring blender, and stored at $4{ }^{\circ} \mathrm{C}$ for mycotoxins analysis (Magnoli et al. 1999; Melcion et al. 1997).

\section{Statistical analysis}

Analysis of variance was conducted for all parameters using the SAS software program NC 27513, USA. Means of the aflatoxins, fumonisin, and frequency of fungi were compared using LSD 0.05 and $T$ test $(P \leq 0.05)$. The correlation between the mycotoxins and the different parameters (moisture and temperature) were also determined.

\section{Results}

Moisture contents in poultry ration samples collected from areas under study

Data in Table 1 show mean of colonization of fungi associated with samples collected from all sources under study. Maximum mean of colonization given was 83 colonies confined with $10 \%$ moisture content in sample collected from Sana'a poultry farm, a farm in which chickens were suffering from dwarfism or loss of weight as reported by the farm owner. Other sample range of moisture contents percentage range was $9.4-13.6 \%$ differed significantly. The least significant mean of company confined with $12.1 \%$ moisture content in samples was collected from Sana'a.

\section{Isolation and identification of fungi}

The most frequent fungi are shown in Table 2. The results indicated that the most dominant fungi were Fusarium sp., Aspergillus spp., and Penicillium spp., and they appear in high frequency in most of poultry ration samples.

Isolation and identification of fungi associated with poultry ration samples collected from four governorates in Yemen proved that fungi isolated are Fusarium moniliforme, Aspergillus flavus, A. carneus, A. candidus, A. niger, Penicillium chrysogenium, Penicillium spp., Mucor sp., and Rhizopus nigricans.

\section{Frequency of fungi isolated from poultry ration samples collected from poultry ration supply companies}

Data in Fig. 1 and Table 3 showed the frequency and species of molds in samples collected from poultry ration supply companies in Sana'a and Taiz governorates. Means of Fusarium moniliforme frequency percentage prevailed from stock solution prepared were 66.7, 23.5, 70.6, 33.3, and $0 \%$ in the five samples tested, respectively. Aspergillus flavus showed 16.7, 17.6, 2.9, 36.1, and 5.9\% for the same samples tested. Penicillium spp. range of occurrence in the five samples collected was 6.7-13.9\%. Other fungi occurrence was either negligible or zero. The most significant mean of occurrence (38.82\%) was given by Fusarium moniliforme, followed by (15.84\%) given by Aspergillus flavus and $16.44 \%$ given by Aspergillus candidus. Other fungi isolated from samples collected from poultry ration supply companies in Sana'a did not show significant occurrence. While the means of fungi in Taiz company occurrence frequency prevailed from stock solution given by Aspergillus flavus isolated from five samples tested were 52.4, 41.2, 5.9, 50, and $29.4 \%$, respectively. Fusarium moniliforme occurrence means were 21.5, 35.3, 64.7, 18.8, and 5.9\% for the same samples, respectively. Other fungi occurrence percentage was not significant. The highest significant mean of occurrence recorded was given by A. flavus (35.78\%), (Fig. 1 and Table 3). 
Table 1 Mean of moisture contents \% (M.C.) in poultry ration samples collected from four governorates

\begin{tabular}{lllllllll}
\hline Samples & location & s1 & s2 & s3 & s4 & s5 & Mean & SD \\
\hline Farmer & Sana'a & $11.10 \%$ & $10.90 \%$ & $10.50 \%$ & $11.30 \%$ & $10.70 \%$ & $10.75 \%$ & $0.46 \%$ \\
& Taiz & $18.30 \%$ & $8.90 \%$ & $8.70 \%$ & $7.90 \%$ & $7.70 \%$ & $10.30 \%$ & $4.50 \%$ \\
& Dhamar & $9.80 \%$ & $11.20 \%$ & $8.40 \%$ & $9.6 \%$ & $10.0 \%$ & $9.80 \%$ & $1.40 \%$ \\
& Ibb & $9.35 \%$ & $10.10 \%$ & $11.10 \%$ & $8.40 \%$ & $11.60 \%$ & $10.11 \%$ & $1.29 \%$ \\
\multirow{3}{*}{ Company } & Sana'a & $11.70 \%$ & $11.20 \%$ & $13.60 \%$ & $9.40 \%$ & $12.10 \%$ & $11.60 \%$ & $1.52 \%$ \\
& Taiz & $9.10 \%$ & $9.80 \%$ & $15.60 \%$ & $9.70 \%$ & $11.00 \%$ & $11.04 \%$ & $2.64 \%$ \\
\hline
\end{tabular}

\section{Occurrence frequency of isolated fungi in samples collected from farmer's poultry farms in four governorates}

Data in (Fig. 2) indicated that range of Aspergillus flavus associated with poultry ration samples in Sana'a was (17.2\%). The highest range of occurrence having a mean of (28.7\%) was given by Fusarium moniliforme, followed by (24.8\%) given by Aspergillus carneus and (17.9\%) was given by Penicillium chrysogenum. Other fungi isolated were with negligible occurrence. Samples of poultry rations collected from Sana'a poultry farms proved that samples collected from Sana'a area ranked the most contaminated poultry ration samples (27\%). Samples of poultry rations collected from Taiz farms show that for Aspergillus flavus occurrence was (15.6\%). However, Fusarium moniliforme contaminating poultry ration samples in Taiz has the highest mean of $48.8 \%$, followed by $21.3 \%$ given by Penicillium chrysogenum. Other fungi listed in poultry ration samples in Taiz were $19 \%$.

The highest significant occurrence frequency range of Aspergillus flavus was given in Ibb area with mean of (14.4\%). However, in Ibb area, Fusarium moniliforme was $50 \%$. Other fungi isolated from ration samples were minors. Total percentage of occurrence of molds in Ibb poultry farms was $26 \%$.

In Dhamar area, Aspergillus flavus isolated from ration samples showed an occurrence frequency with a mean of (22.9\%). While Fusarium moniliforme occurrence was

Table 2 The most dominant of fungi isolated from poultry ration samples collected from four governorates

\begin{tabular}{ll}
\hline Fungi & Identification \\
\hline Fusarium spp. & F. moniliforme \\
Aspergillus spp. & A. flavus \\
& A. carneus \\
& A. candidas \\
Penicillium spp. & A. niger \\
Mucor sp. & P. chrysogenum \\
Rhizopus sp. & P. sp \\
\hline
\end{tabular}

(55.7\%). Total percentage of occurrence percentage of molds in Ibb poultry farms was $28 \%$.

\section{Determination of aflatoxins and fumonisins in poultry ration samples collected from poultry ration supply companies}

Data in Table 4 showed means of aflatoxins and fuminosin levels in poultry ration samples. Samples collected from Sana'a poultry ration supply companies (SPRSC) contained $1.6 \mathrm{ppb}$ aflatoxins and $2.8 \mathrm{ppm}$ fumonisins mycotoxins; the highest level for fumonisins shows about $5.9 \mathrm{ppm}$. Aflatoxins in samples collected from Taiz poultry ration supplies companies (TPRSC) were higher (28.5 ppb) than those reported in SPRSC samples about $45 \mathrm{ppb}$. However, fumonisins detected in poultry samples collected from TPRSC were less $(0.76 \mathrm{ppm})$ than those detected in SPRSC samples.

Determination of aflatoxin and fumonisin levels in poultry ration samples collected from farmer's poultry farms in four governorates

Data in Table 5 indicate that the aflatoxin level in Sana'a farmer's poultry farms ration some sample contained the highest significant levels of aflatoxins (39 ppb), while some samples was observed only (2.3 ppb).

The sample which collected from Taiz farmer's poultry farms and samples in Dhmar farmer's poultry farms showed the highest significant level of aflatoxins (42.5 $\mathrm{ppb})$. Other samples collected from Taiz poultry farms showed also significant concentration $21 \mathrm{ppb}$ from other samples which were observed at $3.8 \mathrm{ppb}, 1.5 \mathrm{ppb}$, and $1.1 \mathrm{ppb}$. In Dhmar poultry farms, the aflatoxin level average between $14 \mathrm{ppb}$ and $2.7 \mathrm{ppb}$ were detected in samples.

In Ibb poultry farms, some samples showed highly significant levels of $39 \mathrm{ppb}$ and $38.5 \mathrm{ppb}$ of aflatoxins. The mean of aflatoxins in Ibb poultry farms was $28.97 \mathrm{ppb}$. Concentrations of aflatoxins in the four governorates differ significantly where Ibb and Taiz showed the highest levels of aflatoxins determined (Table 5).

The highest ever concentration of fumonisins was detected in sample were collected from Sana'a, Ibb, and Taiz poultry farms 5, 4.3, and 3 ppm respectively. 


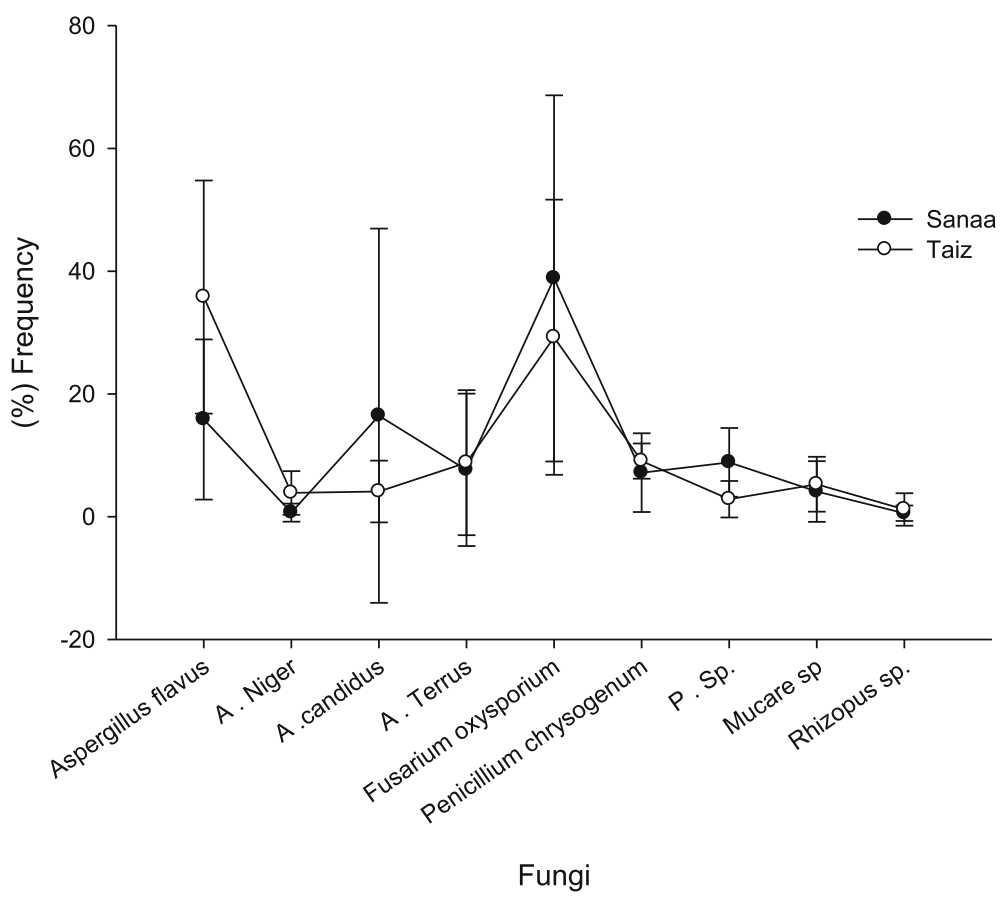

Fig. 1 Occurrence and frequency (\%) of fungi in Sana'a and Taiz companies

Mean of fumonisins concentration in samples collected from Dhmar was $0.67 \mathrm{ppm}$, reflecting the least amount detected.

Effect of three moisture content levels on concentrations of aflatoxins and fumonisins produced in poultry rations The results indicated in Fig. 3 the effect of three levels of moisture contents on means of aflatoxins and fumonisins production at $15 \%$ moisture content, where aflatoxins mean detected was $3.97 \mathrm{ppb}$. While at $25 \%$ moisture content, aflatoxins produced significantly increased up to $16 \mathrm{ppb}$ in comparison with that given by lower ones mentioned.
For fumonisins produced at the three levels of moisture contents used, means of fumonisins detected were $0.20 \mathrm{ppm}, 0.35 \mathrm{ppm}$, and $0.26 \mathrm{ppm}$ at $15 \%, 20 \%$, and $25 \%$ M.C. respectively. No significant difference for fumonisin levels detected was given at all moisture content levels tested.

Effect of three levels of temperature on concentrations of aflatoxins and fumonisins produced in poultry rations Effect of temperature on concentration of aflatoxins and fumonisins produced is observed in Fig. 4. Mean of aflatoxins produced at $15^{\circ} \mathrm{C}$ was $3.6 \mathrm{ppb}$. While highly significant increase in aflatoxins produced at $25^{\circ} \mathrm{C}$ was $25.2 \mathrm{ppb}$.

Table 3 Levels of fungi in poultry ration samples collected from poultry ration supply companies

\begin{tabular}{|c|c|c|c|c|c|c|c|c|c|c|c|c|c|}
\hline \multirow[t]{2}{*}{ Fungi } & \multirow{2}{*}{$\begin{array}{l}\text { Locality } \\
\text { Sample }\end{array}$} & \multicolumn{6}{|c|}{ Sana'a com. \% } & \multicolumn{6}{|c|}{ Taiz com. \% } \\
\hline & & 1 & 2 & 3 & 4 & 5 & Mean & 1 & 2 & 3 & 4 & 5 & Mean \\
\hline \multicolumn{2}{|c|}{ Aspergillus flavus } & 16.7 & 17.6 & 2.9 & 36.1 & 5.9 & 15.84 & 52.4 & 41.2 & 5.9 & 50 & 29.4 & 35.78 \\
\hline \multicolumn{2}{|c|}{ Aspergillus niger } & 3.3 & 0 & 0 & 0 & 0 & 0.66 & 7.1 & 0 & 0 & 6.3 & 5.9 & 3.86 \\
\hline \multicolumn{2}{|c|}{ Aspergillus candidus } & 0 & 0 & 8.8 & 2.8 & 70.6 & 16.44 & 2.4 & 0 & 0 & 6.3 & 11.8 & 4.1 \\
\hline \multicolumn{2}{|c|}{ Aspergillus carneus } & 0 & 29.4 & 0 & 2.8 & 5.9 & 7.62 & 2.4 & 5.9 & 0 & 6.3 & 29.4 & 8.8 \\
\hline \multicolumn{2}{|c|}{ Fusarium moniliforme } & 66.7 & 23.5 & 70.6 & 33.3 & 0 & 38.82 & 21.4 & 35.3 & 64.7 & 18.8 & 5.9 & 29.22 \\
\hline \multicolumn{2}{|c|}{ Penicillium chrysogenum } & 6.7 & 17.6 & 5.9 & 5.6 & 0 & 7.16 & 9.5 & 5.9 & 11.8 & 6.3 & 11.8 & 9.06 \\
\hline \multicolumn{2}{|c|}{ Penicillium spp. } & 6.7 & 11.8 & 0 & 13.9 & 11.8 & 8.84 & 2.4 & 5.9 & 0 & 0 & 5.9 & 2.84 \\
\hline \multicolumn{2}{|c|}{ Mucor sp. } & 0 & 0 & 11.8 & 2.8 & 5.9 & 4.1 & 2.4 & 5.9 & 11.8 & 6.3 & 0 & 5.28 \\
\hline \multicolumn{2}{|c|}{ Rhizopus sp. } & 0 & 0 & 0 & 2.8 & 0 & 0.56 & 0 & 0 & 5.9 & 0 & 0 & 1.18 \\
\hline
\end{tabular}

LSD for fungi, $0.05 ; F=11.9 ;$ locality $(L)=5.6 ; F \times L=16.8$ 


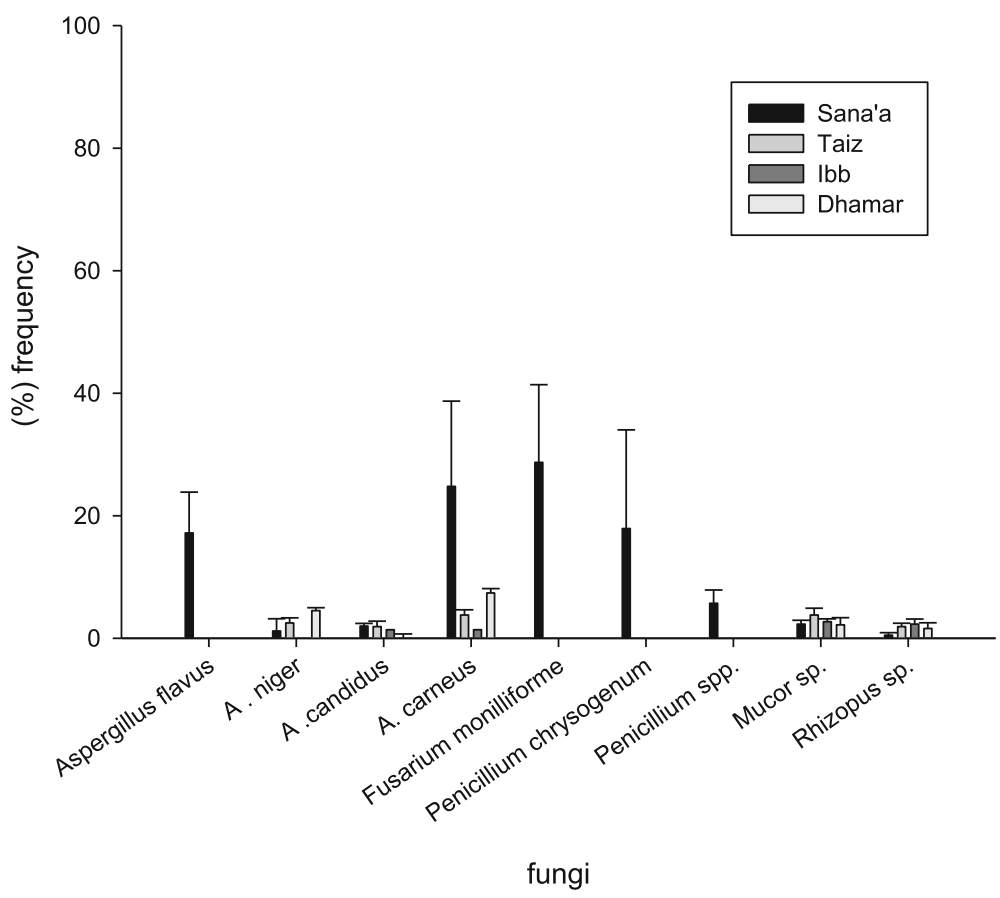

Fig. 2 Effect of locality on occurrence of fungi in samples collected from farmers in four governorates (Sana'a, Taiz, Ibb, and Dhamar

However, secretion of aflatoxins by $A$. flavus decreased (9.93 ppb) as temperature increased up to $35^{\circ} \mathrm{C}$.

For fumonisin levels produced at the three levels of temperature used, means detected were $1.3 \mathrm{ppm}, 1.68$ $\mathrm{ppm}$, and $0.54 \mathrm{ppm}$ respectively. No significant difference for fumonisin levels was detected at all temperature levels tested.

Effect of temperature on concentration of aflatoxins and fumonisins produced was studied. Aflatoxins mean produced at $15^{\circ} \mathrm{C}$ was 3.6 while highly significant increase in aflatoxin mean $25.2 \mathrm{ppb}$ was produced at $25^{\circ} \mathrm{C}$. At $35^{\circ} \mathrm{C}$, mean of aflatoxins determined in three replicated ration samples tested was $9.93 \mathrm{ppb}$.

\section{Discussion}

Moisture contents in poultry ration samples collected from areas under study

However, other samples collected from Sana'a did not differ significantly in either for their moisture contents or for their mean of colonization. In Taiz, moisture contents of samples differed significantly and ranged 9.1-18.3\%. For ration samples collected from farmer's poultry farms, range of moisture contents for the same samples was $7.7-18.3 \%$. However, the highest colonization was coincided with the highest level of moisture content percentage. The least samples colonization significance was given by all commercial samples. This result was in agreement with the reports by Gloria et al., Shetty (1997), and Bhat (1997).

\section{Isolation and identification of fungi}

Data on fungi occurring in poultry ration obtained in Yemen are coincided with those reported in different countries by Abdel-mallek et al. (1993), Nijs and De-Nijs (1997), and Bottalico (1997). Results of the present work showed a predominance of the genera obtained (F. moniliforme, A. flavus) with those reported by Dasilva et al. (2000) who reported the predominance of the genera

Table 4 Means of aflatoxins and fumonisins in ration samples collected from poultry ration supply companies

\begin{tabular}{|c|c|c|c|c|c|c|}
\hline \multirow{3}{*}{$\begin{array}{l}\text { Mycotoxins } \\
\text { Sample }\end{array}$} & \multicolumn{6}{|c|}{ Locality } \\
\hline & \multicolumn{3}{|c|}{ Sana'a poultry companies } & \multicolumn{3}{|c|}{ Taiz poultry companies } \\
\hline & 1 & 2 & 3 & 1 & 2 & 3 \\
\hline Aflatoxins (ppb) & 0.7 & 0.2 & 3.8 & 14.5 & 45 & 26 \\
\hline Fumonisins (ppm) & 1.5 & 5.9 & 1 & 0.65 & 0.93 & 0.7 \\
\hline
\end{tabular}

LSD for 0.05; aflatoxins $\mathrm{Af}=24.88$; fumonisins $\mathrm{Fu}=4.33$ 
Table 5 Mean level of aflatoxins and fumonisins in poultry ration samples collected from farmer's poultry farms

\begin{tabular}{|c|c|c|c|c|c|c|c|c|c|c|c|c|c|c|c|c|c|c|c|}
\hline \multirow[t]{3}{*}{ Mycotoxins } & \multicolumn{11}{|c|}{ Locality } & \multicolumn{8}{|c|}{ Locality } \\
\hline & \multicolumn{6}{|c|}{$\begin{array}{l}\text { Sana'a } \\
\text { Samples }\end{array}$} & \multicolumn{5}{|c|}{$\begin{array}{l}\text { Taiz } \\
\text { Samples }\end{array}$} & \multicolumn{5}{|c|}{$\begin{array}{l}\text { lbb } \\
\text { Samples }\end{array}$} & \multicolumn{3}{|c|}{$\begin{array}{l}\text { Dhamar } \\
\text { Samples }\end{array}$} \\
\hline & 1 & 2 & 3 & 4 & 5 & 6 & 1 & 2 & 3 & 4 & 5 & 1 & 2 & 3 & 4 & 5 & 1 & 2 & 3 \\
\hline Aflatoxins ppb & 39 & 2.8 & 2.3 & 3.3 & 3.8 & 22 & 42.5 & 1.1 & 1.5 & 21 & 3.8 & 0.6 & 4.5 & 4.3 & 38.5 & 39 & 14 & 42.5 & 2.7 \\
\hline Fumonisins ppm & 0.3 & 0.5 & 5 & 0.5 & 0.9 & 0.4 & 1 & 0.9 & 0.8 & 3 & 1.3 & 0.9 & 4.3 & 0.9 & 0.9 & 0.9 & 0.85 & 0.66 & 0.5 \\
\hline
\end{tabular}

LSD 0.05 for aflatoxins $\mathrm{Af}=24.3$; fumonisins $\mathrm{Fu}=1.94$

Phoma (57.1\%), Aspergillus (42.7\%), Fusarium (25.0\%), and Rhizopus (21.4\%).The most frequently found species were Aspergillus flavus and Fusarium moniliforme. Survey of mold count and fungal species on feed samples proved that Aspergillus, Penicillium, and Fusarium were the most frequent genera. These results are also in agreement with the report by Castella et al. (1999a) and Dasilva et al. (2000). Therefore, only Fusarium moniliforme and Aspergillus flavus were subjected for further studies.
Occurrence frequency of isolated fungi in samples collected from farmer's poultry farms in four governorates

Occurrence and frequencies of fungi isolated from samples collected from poultry ration supply companies in Sana'a and Taiz showed that Fusarium moniliforme ranked the most contaminant frequently occurring in samples collected from poultry ration supply companies in Sana'a followed by Aspergillus flavus. For samples collected from

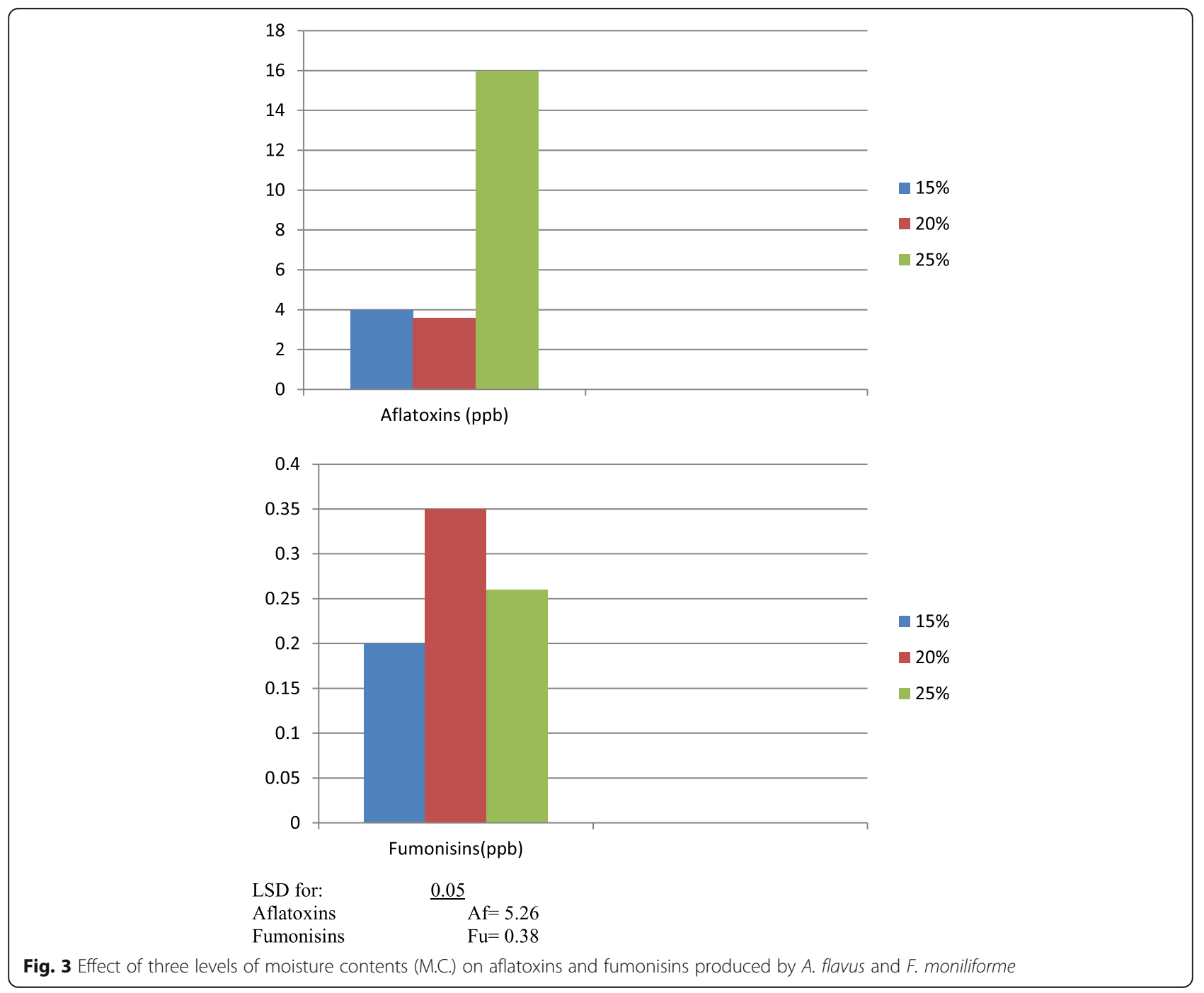




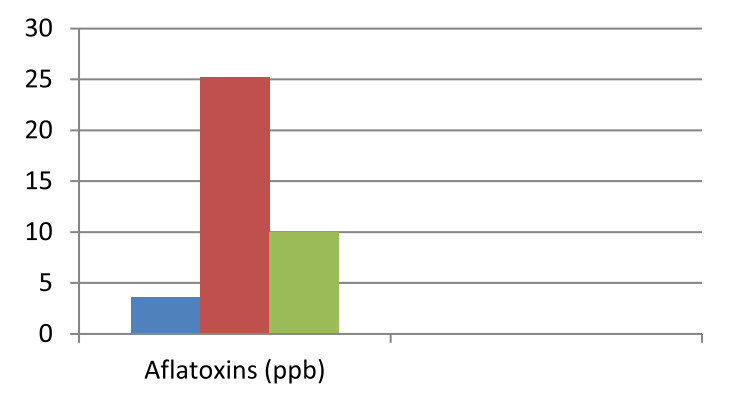

\section{- Temperature $15 \mathrm{C}^{\circ}$}

- Temperature $25 \mathrm{C}^{\circ}$

- Temperature $35 \mathrm{C}^{\circ}$

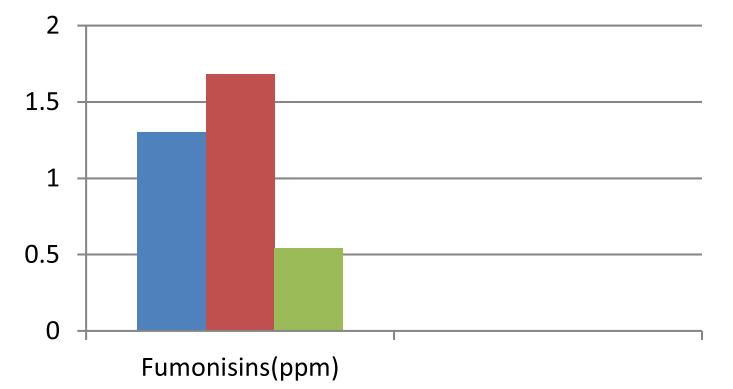

- Temperature $15 \mathrm{C}^{\circ}$

- Temperature $25 \mathrm{C}^{\circ}$

- Temperature $35 \mathrm{C}^{\circ}$

$\begin{array}{lr}\text { LSD for: } & \underline{0.05} \\ \text { Aflatoxins } & \mathrm{Af}=19.3 \\ \text { Fumonisins } & \mathrm{Fu}=2.57\end{array}$

Fig. 4 Effect of three levels of temperature on aflatoxins and fumonisins produced by A. flavus and F. moniliforme

Taiz poultry ration supply companies, data proved that Aspergillus flavus exhibited the most frequently occurring contaminant followed by Fusarium moniliforme. Other contaminants are either negligible or absent. Contamination with fungi increased in samples collected from poultry farms mostly in all governorates. On the other hand, Fusarium moniliforme was also dominant in samples collected from farmer's poultry farms in all governorates followed by Aspergillus flavus. Results strongly indicated that poultry rations distributed to poultry farmers were already contaminated at the source of origin. Three genera of fungi-Aspergillus, Penicillium, and Fusarium (Gibberella)-are the ones involved most frequently in cases of mycotoxin contamination in corn, small grains, and soybeans which are the major constituent elements of poultry rations, and the Fusarium was detected in $83 \%$ of 69 cereal samples from batches intended for food or feed production Nijs and De-nijs (1997) reported that several Fusarium species occurring on pre-harvest cereals in Europe cause widespread stalk and ear rot of maize and head blight of small cereals. They also lead to the accumulation of mycotoxins in infected ears. There is increasing evidence for the occurrence of toxigenic strains of Fusarium moniliforme [Gibberella fujikuroi] and FB1 mycotoxin in infected maize ears all over Europe. Such reported data are strong evidence explaining how the poultry ration constituents imported from abroad into Yemen are born with primary source of infection and molds. Such fact inconceivably also harden the beliefs in that contamination of poultry ration formulated from infected maize, soybeans, and cereals used in poultry ration formulation starts at the growing duration in the field. In case of maize contamination with Aspergillus flavus, three Aspergillus species were isolated from different agroecological zones, with Aspergillus flavus being the most prevalent. The country-wide mean percentage of kernel infection was c. $20 \%$ in two successive years (Setamou et al. 1997). Data obtained in the current study in Yemen also are in agreement with these reports by Magnoli et al. (1999) and Orsi et al. (2000) who reported that microbiological analysis revealed a predominance of Fusarium species, which presented the greatest total number of CFUs per gram in three maiz hybrids, followed by Penicillium spp., Aspergillus spp., and 10 other fungal genera. Fusarium moniliforme [Gibberella fujikuroi] was the most prevalent species (59.2\% of Fusarium isolates in Br 201, 55.4\% in C 125 and 69.2\% in Cx 322 (Chau et al. 1997). On the other hand, soybeans which is a major element of poultry ration constituent is also subjected to infection by several contaminant and has been evaluated by Park et al. (1999) who isolated a total of 52 isolates of Fusarium species obtained from soybean seeds from various parts of the Korea Republic and identified as F. oxysporum, $F$. moniliforme [Gibberella fujikuroi], F. semitectum [F. pallidoroseum], F. solani, F. graminearum [Gibberella zeae], or F. lateritium [G. baccata]. Moreover, data are in agreement with findings reported by Orsi et al. (2000), Proctor et al. (1999), Jindal et al. (1999), and Ono et al. (1999). 
The performance of fungi colonization and the level of moisture content in the collected poultry ration samples collected from four governorates under study were investigated. All rates of colonization differed significantly by samples. However, the highest rate of colonization (83 colonies) was reported in sample delivered by a farmer owing a poultry farm suffering from chicken dwarfism or growth loss in Sana'a District. Data also indicated that the high degree of colonization was for samples collected from farmer's poultry farms in general. Although contamination was less at the origin of distribution by poultry ration supply companies, samples were still significantly high. It can be concluded that under such circumstances, farmers are used to buy already contaminated poultry rations and moreover, source of contamination is the poultry ration raw materials imported from abroad. Such assumption was supported by the uniformity of contaminant genera isolated from approximately all samples collected from four governorates under study. Such findings in fact support such assumption data reported by several investigators who confirmed that infection of the imported raw materials used in formulating locally poultry rations started usually at the source of origin during crop growing in fields, (Bottalico, 1997; Park et al. 1999; Orsi et al. 2000; Dasilva et al. 2000; Chau et al. 1997; Jindal et al. 1999; Ono et al. 1999; Gonzalez et al. 1999).

\section{Determination of aflatoxins and fumonisins in poultry ration samples collected from poultry ration supply companies}

It is concluded that contamination of samples with mycotoxins at Sana'a poultry ration supply companies was less than that detected at Taiz supply companies. Data are in agreement with reports raised by Dasilva et al. (2000) who showed that $12.8 \%$ of samples tested were contaminated with aflatoxin B1 and 74.2\% were contaminated with fumonisin B1. Aflatoxin production is conditioned by abiotic and biotic (genetic) parameters. Among the isolates, Aspergillus flavus and Aspergillus parasiticus produced AFB, Aspergillus flavus produced AFG 1, Aspergillus ochraceus produced ochratoxin-A, Aspergillus japonicus produced sterigmatocystin, and Penicillium citrinum produced citrinin. AFB in the range $333-10,416 \mu \mathrm{g} / \mathrm{kg}$ was produced by Aspergillus spp. in rice, pulses, and oilseeds (Martins et al. 1999). Data also are in agreement with findings reported by Zhang et al. (1997) who studied 246 samples and found that of 164 maize samples collected from areas in which the risk of human esophageal cancer (HEC) is high, fumonisins were detected in 106 samples at $0.5-16.0 \mathrm{ppm}$, but of 82 samples collected from HEC low risk areas, fumonisins at $0.5-1.5 \mathrm{ppm}$ were found in 23 samples. The highest level of aflatoxins detected in Sana'a area was 22 ppb. A sample delivered by a farmer owing a poultry farm suffering from chicken dwarfism or loss growth. However, mean of aflatoxins in ration samples collected from Sana'a poultry farms was $12 \mathrm{ppb}$.

\section{Determination of aflatoxin and fumonisin levels in poultry ration samples collected from Farmer's poultry farms in four governorates}

In general, aflatoxin concentrations in ration samples differed significantly, but no significant different was detected in the case of fumonisins.

Similar results were reported by Magnoli et al. (1999) who investigated the production of fumonisins by toxigenic Fusarium species strains and in 158 samples of poultry feeds collected from a factory located in the department of Rio Cuarto, Cordoba province, Argentina. Also, they showed that toxin produced in highest levels by the majority of the strains was FB1. Moreover, they confirmed that the low level of fumonisins detected (0.3-5.0 ppm.) in all samples collected indicates that a genetically component of $F$. moniliforme biotype is responsible for the pattern of Fusarium moniliforme toxigenic effect in poultry ration samples tested. Also Bottalico et al. (1997) in Accra reported that 15 maize samples from 4 markets and processing sites were analyzed for fumonisins B1, B2, and B3. All samples contained fumonisins ranged from 70 to $4222 \mathrm{mg} / \mathrm{kg}$. Additional studies on maize samples from 15 processing sites in Accra revealed a co-occurrence of both fumonisins and aflatoxins in 8/15 samples (Kpodo et al. 2000). Data are also in agreement with these reported by Ali et al. (1998) and Proctor et al. (1999).

Effect of three moisture content levels on concentrations of aflatoxins and fumonisins produced in poultry rations Data showed that effect of three levels of moisture contents on means of aflatoxins and fumonisins production was different by the level of sample moisture content. No significant difference for aflatoxins produced at 15-20\% moisture content was determined. Aflatoxins, zearalenone, and ochratoxin A, and moisture levels and average contamination by aflatoxins B1 + G1 were 14.9, 13.9, and $4.3 \mu \mathrm{g} / \mathrm{kg}$, respectively when $27.7 \%$ of the samples had moisture levels above 14.5\% (Gloria et al. 1997). Also Magan et al. (1984) concluded that Aspergillus flavus grows best on corn at $18.0-18.5 \%$ moisture. Moisture content below $13 \%$ prevents invasion by Aspergillus flavus. Fungal growth may begin on corn at moisture content lower than $18.0 \%$. As the fungus grows, the respiration occurs, releasing heat and moisture into the surrounding environment in the grain mass. An increase in the moisture content and temperature of the surrounding corn cause a hot spot. If moisture content and temperature continue to rise, the environment for Aspergillus flavus becomes more favorable. Fungal growth is best at $18 \%$ 
moisture. At $20 \%$ moisture content and above, other fungi grow better and crowd out Aspergillus flavus.

Data reported here also indicated that at $25 \%$ moisture content, a significant difference between aflatoxins produced at higher moisture contents and at the lower ones tested was determined. Mean of fumonisin levels produced at the three levels of moisture contents used. No significant difference for fumonisin levels detected was given at all moisture contents tested. Data obtained are supported by Shetty and Bhat (1997) who reported that fumonisins B1 contamination in the poultry feed samples ranged from 0.02 to $0.26 \mathrm{mg} / \mathrm{kg}$. Such findings emphasized the importance of small differences in $\mathrm{MC}$ in determining safe storage conditions. The rapid moisture equilibration between wet and dry corn indicated that corn could be blended with minimal risk of mold damage or aflatoxins contamination if the average $\mathrm{MC}$ of the blend is low enough to prevent mold growth (Sauer and Burroughs, 1980).

\section{Effect of three levels of temperature on concentrations of aflatoxins and fumonisins produced in poultry rations}

Thus, finding presented here proved that aflatoxins secretion by (A.) flavus decreased as temperature increased over $25^{\circ} \mathrm{C}$ up to $35^{\circ} \mathrm{C}$. Fusarium tricinctum and some strains of $F$. graminearum, F. equiseti, F. sporotrichioides, $F$. poae, and F. lateritium produced T-2 and other toxic trichothecenes. These fungi commonly attack grains and can grow at temperatures from slightly above freezing to about $86^{\circ} \mathrm{F}$. T-2 and HT-2 toxins are produced over a temperature range of $46^{\circ} \mathrm{F}$ to $77^{\circ} \mathrm{F}$, with the maximum production at temperatures below $59^{\circ} \mathrm{F}$. There was a trend toward higher rate of aflatoxin accumulation per percentage of Aspergillus flavus infection (MEdi et al. 1997). The growth rate of G. fujikuroi var. subglutinans was highest at $20^{\circ} \mathrm{C}$ and $25^{\circ} \mathrm{C}$ in maize cultures and at $15 \mathrm{C}^{\circ}$ in rice cultures than in maize, with maximal yield at $25^{\circ} \mathrm{C}$ of $979 \mu \mathrm{g} / \mathrm{g}$ after 2 weeks and $143 \mu \mathrm{g} / \mathrm{g}$ after 3 weeks in maize and rice cultures, respectively (Setamou et al. 1997), Castella et al. (1999b).

Conditions that favor aflatoxin production and the invasion of corn by Aspergillus flavus in the field include drought stress or damage to the corn ear by ear worms or other insects, birds, hail, or early frost. High temperatures, high relative humidity around the kernels, and kernel moisture below 30\% (wet basis) are ideal conditions for fungal invasion of the kernel. The optimum temperature for aflatoxin production in storage is between $25^{\circ} \mathrm{C}$ and $32^{\circ} \mathrm{C}\left(77^{\circ} \mathrm{F}\right.$ and $\left.90^{\circ} \mathrm{F}\right)$. Kernels with a moisture content below $15 \%$ are at less risk of mold growth and aflatoxin production, while an optimum kernel moisture is around $18 \%$ and an optimum relative humidity in the bin is $85 \%$ or higher. But the field conditions that favor Fusarium to invade these grain crops include warm, moist weather. Blight symptoms can develop within 3 days after infection when temperatures range between $25^{\circ} \mathrm{C}$ and $30^{\circ} \mathrm{C}$ and moisture is continuous. Plants appear most susceptible when they are infected at the flowering stage of development. Ochratoxins occur most readily in storage of high-moisture (greater than 22\%) grains. Therefore, the only recommended control is to keep grains cool and dry in storage (Proctor et al. 1999). The amount of aflatoxin produced in storage is determined by storage conditions. The most important factors are grain moisture content and temperature. Optimum temperatures for Aspergillus flavus to grow are $80-90^{\circ} \mathrm{F}$; optimum grain moisture content is $18 \%$. Damaged corn also favors the growth of (A.) flavus. Importantly, aflatoxin concentration never decreases in storage; it only increases or remains the same (Sauer and Burroughs, 1980; Magan et al. 1984).

\section{Conclusion}

This report is the first one in this field to investigate the contamination of poultry ration by fungi. Those fungi effects on industry of poultry in Yemen by contaminating the rations and by producing many metabolites may have an effect on growth of poultry and may cause many diseases. Many diseases were observed in many poultry farms like dwarfism and death of big numbers of chicken in different sites. The results indicated high frequency of fungi in all samples which were collected from the big stores in main governorates. The most fungi showed are the most dangerous and have the ability to produce many metabolites like aflatoxins and fumonisin. These results open the door for many future studies to investigate the contamination of fungi on all the cereals which were imported from other countries. As well as to investigate the mycotoxins in the food and the best quality of stores to avoid regrowth of fungi and production of metabolites.

\section{Acknowledgements}

This work was supported by without border cooperation, Sana'a, Yemen, and the authors are thankful for the professor saeed alghalibi professor of microbiology, biology department- science college for helping in identification of fungi.

\section{Funding}

This work was funding by the without border cooperation, Sana'a, Yemen by supply the work by the provision aflatoxins and fumonisin standards and other chemicals which using for extraction and determination of mycotoxins from Bio-farm company, Germany.

\section{Availability of data and materials}

Not applicable

\section{Authors' contributions}

All authors read and approved the final manuscript.

Ethics approval and consent to participate Not applicable

Consent for publication

Not applicable 


\section{Competing interests}

The authors declare that they have no competing interests.

\section{Publisher's Note}

Springer Nature remains neutral with regard to jurisdictional claims in published maps and institutional affiliations.

\section{Author details}

'Plant Protection, Agriculture College Sana'a University, Sana'a, Yemen. ²Blood Searching Department, Medicine College Sana'a University, Sana'a, Yemen. ${ }^{3}$ Biology Department, Education College Albayda'a University, Albayda'a, Yemen. ${ }^{4}$ Biotechnology and Food Technology, Dhamar University, Dhamar, Yemen. ${ }^{5}$ Yemen, Albayda'a University, P.O Box 38018, Albayda'a, Yemen.

Received: 27 June 2018 Accepted: 29 November 2018

Published online: 19 December 2018

\section{References}

Abbas HK, Smeda RJ, Gerwick BC, Shier WT (1999) Fumonisin B1 from the fungus Fusarium moniliforme causes contact toxicity in plants: evidence from studies with biosynthetically labeled toxin. J Nat Toxins 8(3):405-420

Abdel-mallek AY, El-maraghy SSM, Hasan HAH (1993) Mycotoxin producing potential of some Aspergillus, Penicillium and fusarium isolates found on corn grains and sunflower seed in Egypt. J Islamic Acad Sci 6(3):189-192

Alexopoulos CJ, Mims CW (1979) Introductory mycology. Newyourk chrichester Brisbane Toronto

Ali N, Sardjono YA, Yoshizawa T (1998) Natural co-occurrence of aflatoxins and Fusarium mycotoxins (fumonisins, deoxy-nivalenol, nivalenol and zearalenone) in corn from Indonesia. Food Addit Contam 15:377-384

AUMC.(Assiut University Mycological Centre). Indentification of Aspergillus species and its teleomorphs with special attention to the species which contamination food materials; During 24-29 march (2001)

Begum F, Samajpati N (2000) Mycotoxin production on rice, pulses and oilseeds. Naturwissenschaften 87:275-277

Bottalico A (1997) Toxigenic Fusarium species and their mycotoxins in preharvest cereals in Europe. Bull Inst Compr Agric Sci Kinki Univ 5:47-62

Castella G, Bragulat MR, Cabanes FJ ((1999b)) Surveillance of fumonisins in maizebased feeds and cereals from Spain. J Agric Food Chem 47(11):4707-4710

Castella G, Munkvold GP, Imerman P, Hyde WG (1999a) Effects of temperature, incubation period and substrate on production of fusaproliferin by Fusarium subglutinans ITEM 2404. Natural-Toxins 7(4):129-132

Chau NT, Hieu LH, Lam NT, Huong NM, Tra NH, Quang TV (1997) The occurrence of aflatoxin B1 and ochratoxin a in maize harvested in Vietnam in 1995-1996. Mycotoxins 45:57-62

Christensen CM (1969) Influence of moisture content, temperature, and storage upon invasion of rough rice by storage fungi. Phytopathology 59:145-148

Dasilva JB, Pozzi CR, Mal-lozzi AB, Ortega EM, Correa B (2000) Mycoflora and occurrence of aflatoxin B 1 and fumonisin B 2 during storage of Brazilian sorghum. J Agric Food Chem 48:4352-4356

Desjardins AE, Gyanu M, Plattner RD, Maragos CM, Krishna S, McCormick SP, Manandhar G, Shrestha K (2000) Occurrence of Fusarium species and mycotoxins in Nepalese maize and wheat and the effect of traditional processing methods on mycotoxin levels. J Agric Food Chem 48(4):1377-1383

Gloria EM, Fonseca H, Souza IM (1997) Occurrence of mycotoxins in maize delivered to the food industry in Brazil. Trop Sci 37(2):107-110

Gonzalez HHL, Martinez EJ, Pacin M, Resnik SL, Sydenham EW (1999) Natural Cooccurrence of fumonisins, deoxynivalenol, zearalenone and aflatoxins in field trial corn in Argen-tina. Food Addit Contam 16:565-569

Jindal N, Mahipal SK, Rottinghaus GE (1999) Occurrence of fumonisin B 1 in maize and poultry feeds in Haryana, India. Mycopathologia 148:37-40

Kpodo K, Thrane U, Hald B (2000) Fusaria and fumonisins in maize from Ghana and their co-occurrence with aflatoxins. Int J Food Microbiol 61:147-157

Magan N, Cayley GR, Lacey J (1984) Effect of water activity and temperature on mycotoxin production by alternaria alternata in culture and wheat grain. Appl Environ Microbiol 47:1113-1117

Magnoli CE, Saenz MA, Chiacchiera SM, Dalcero AM (1999) Natural occurrence of Fusarium species and fumonisin-production by toxigenic strains isolated from poultry feeds in Argentina. Mycopathologia 145(1):35-41

Martins HML, Bernardo FMA, Martins MLL. In vitro production of aflatoxins : Revista Portuguesa de Ciencias Veterinarias; Oct.-Dec., 94(532): 177-181 (1999)
Medina-Martinez MS, Mar-Tinez AJ (2000) Mold occurrence and aflatoxin B 1 and fumonisin B 1 determi- nation in corn samples in Venezuela. J Agric Food Chem 48:2833-2836

Melcion D, cahagnier B, Richard-Molard D (1997) Study of the biosynthesis of fumonisins B1, B2 and B3 by different strains of fusarium moniliforme. Lett Appl Microbiol 24:301-305

Menna ME, Lauren DR, Hardacre A, Di-Menna ME (1997) Fusaria and Fusarium toxins in New Zealand maize plants. Mycopathologia 139(3):165-173

Nepote MC, Piontelli LE, Saubois A (1997) Occurrence of Aspergillus flavus strains and aflatoxins in corn from Santa Fe, Argentina. Incidencia de cepas de Aspergillus flavus y aflatoxinas en maiz de Santa Fe, Argentina. Arch Latinoam Nutr 47(3):262-264

Nijs M, De-Nijs M (1997) Public health aspects of Fusarium mycotoxins in food in The Netherlands: a risk assessment, p 140

Ono EYS, Sugiura Y, Homechin M, Kamogae M, Vizzoni E, Ueno Y, Hirooka EY (1999) Effect of climatic conditions on natural mycoflora and fumonisins in freshly harvested corn of the state of Paran,Brazil. Mycopathologia 147:139-148

Orsi RB, Correa B, Possi CR, Schammass EA, Nogueira JR, SMC D, MAB M (2000) Mycoflora and occurrence of fumonisins in freshly harvested and stored hybrid maize. J Stored Prod Res 36(1):75-87

Park J, Lee K, Kim J, Lim S, Seo J, Lee Y, Park JS, Lee KR, Kim JC, Lim SH, Seo JA, Lee YW (1999) A hemorrhagic factor (apicidin) produced by toxic Fusarium isolates from soybean seeds. Appl Environ Microbiol 65(1):126-130

Pascale M, Visconti A, Avantaggiato G, Pronczuk M, Chelkowski J (1999) Mycotoxin contamination of maize hybrids after infection with Fusarium proliferatum. J Sci Food Agric 79(15):2094-2098

Pitt JI (1979) The genus Penicillium and its teleomorphic states Eupenicillium and Talaromyces. Academic Press Inc, London

Pitt Jl, Hocking AD (2013) Fungi and food spoilage. Springer Dordrecht Heidelberg London New York. ISBN 978-0-387-92206-5

Proctor RH, Desjardins AE, Plattner RD, Hohn TM (1999) A polyketide synthase gene required for biosynthesis of fumonisin mycotoxins in Gibberella fujikuroi mating population A. Fungal Genet Biol 27(1):100-112

Ryu D, Bullerman LB (1999) Effect of cycling temperatures on the production of deoxynivalenol and zearalenone by Fusarium graminearum NRRL 5883. Journal-of-Food-Protection 62(12):1451-1455

Sauer DB, Burroughs R (1980) Fungal growth, aflatoxin production, and moisture equilibration in mixtures of wet and dry corn. Phytopathology 70:516-521

Setamou M, Cardwell KF, Schulthess F, Hell K (1997) Aspergillus flavus infection and aflatoxin contamination of preharvest maize in Benin. Plant Dis 81(11): 1323-1327

Shetty PH, Bhat RV (1997) Natural occurrence of fumonisin B1 and its cooccurrence with aflatoxin B1 in Indian sorghum, maize, and poultry feeds. Agric Food Chem 45(6):2170-2173

Tsai GJ, YU SC (1999) Detecting Aspergillus parasiticus in cereals by an enzymelinked immune-sorbent assay. Int J Food Microbiol 50:181-189

Zhang H, Nagashima H, Goto T (1997) Natural occurrence of mycotoxins in corn, samples from high and low risk areas for human esophageal cancer in China. Mycotoxins 44:29-35

\section{Submit your manuscript to a SpringerOpen ${ }^{\circ}$ journal and benefit from:}

- Convenient online submission

- Rigorous peer review

- Open access: articles freely available online

High visibility within the field

- Retaining the copyright to your article

Submit your next manuscript at $>$ springeropen.com 